\title{
Does body mass index in childhood predict restraint eating in early adolescence?
}

\author{
Christine Forrester-Knauss, ${ }^{a, *}$, Sonja Perren ${ }^{b}$, Françoise D. Alsaker ${ }^{a}$ \\ ${ }^{2}$ Department of Psychology, University of Bern, Muesmattstrasse 45, $\mathrm{CH}-3000$ Bern 9, Switzerland \\ bJacobs Center for Productive Youth Development, University of Zürich, Culmannstrasse 1. CH-8006 Zurich, Switzerland
}

Keywords:

Restrained eating

Emotional eating

Body mass index

Body esteem

Emotional symptoms

Childhood

Preadolescence

Longitudinal

\begin{abstract}
The aim of this study was (1) to examine whether childhood BMI is a significant predictor of restrained eating in preadolescents, (2) to investigate gender differences in restrained and emotional eating, and (3) to determine whether emotional problems, and body esteem were related to eating problems of preadolescents. In this longitudinal study with two measurement points, data from 428 children ( $50 \%$ female) were used. At time $1(t 1)$ children were on average 5.9 years old. BMI was assessed using objective measures. At time $2(t 2)$ participants were 12 years old. The adolescents and their parents completed ques* tionnaires assessing restrained and emotional eating, body esteem, emotional problems, and BMI. Multiple regression analysis showed that restrained eating was significantly predicted by $t 1$ BMI, by change in BMI between $t 1$ and $t 2$, and $t 2$ body esteem. Emotional eating was, as expected, not predicted by $t 1$ BMI, but associated with $t 2$ body esteem and $t 2$ emotional problems. Gender was not a significant predictor. The stability of BMI between childhood and preadolescence and its ability to predict restrained eating suggests that it is important to start prevention of overweight, body dissatisfaction and disordered eating at an early age.
\end{abstract}

\section{Introduction}

Little research has investigated risk factors for the development of eating problems from childhood to early adolescence. Preadolescence is a developmental period of significance in relation to the emergence of eating problems (Stice, Agras, \& Hammer, 1999). Research about specific eating problems stich as restrained or emotional eating in children and adolescents suggests relationships with body weight or obesity with a higher likelihood of being overweight in individuals with disordered eating symptoms (Snoek, van Strien, Janssens, \& Engels, 2007). Restrained eating has found to be a risk factor for the development of eating disorders such as anorexia nervosa, bulimia nervosa, or eating disorders not otherwise specified (Fairburn, Cooper, Doll, \& Davies, 2005), and overweight (Haines, Neumark-Sztainer, Wall, \& Story, 2007), or weight gain (Field \& et al., 2003; Neumark-Sztainer, Wall, Story, \& Standish, 2012). To inform prevention of disordered eating and obesity, both important public health concerns (Must \& Strauss, 1999; Neumark-Sztainer, Story, Hannan, Perry, \& Irving, 2002;

\footnotetext{
"Acknowledgements: Funding for this study was provided by a Grant from the Swiss National Science Foundation (National Research Programme 52, Grant No. 4052-69011) to FA and by Grants from the Helvetia Sana Foundation and the Suzamne and Hans Biäsch Foundation for the promotion of Applied Psychology. We thank Professor Susan Paxton for her useful comments on the manuscript. Conflict of interest: The authors declare that there are no conflicts of interest.

* Corresponding author.

E-mail addresses: christine.knauss@psy.unibe.ch (C. Forrester-Knauss), perren@ jacobscenter.unizh.ch (S. Perren), francoise.alsaker@psy.unibe.ch (F.D. Alsaker)
}

Stovitz, Pereira, Vazquez, Lytle, \& Himes, 2008; Gillen, Markey, \& Markey, 2012), investigation of these eating problems and their predictors in early life is of particular significance.

Eating behaviour can be related to factors other than hunger, such as emotional distress or the wish to achieve or maintain a desired weight. Therefore, emotional eating occurs as a response to emotional distress rather than as a response to feelings of hunger. Individuals who restrain their eating suppress their feelings of hunger and reduce their caloric intake which, according to the restraint theory (Polivy \& Herman, 1985), can lead to bingeing and overweight. With the dual pathway model (Stice, 1994; Stice \& Shaw. 2002 ) it was suggested that the development of disordered eating. particularly bulimic behaviour, results from body dissatisfaction via the two mediating pathways restrained eating and negative affect.

In a cross sectional study, it has been shown that eating problems were strongly linked to overweight in a sample of preadolescent children (Schuetzmann, Richter-Appelt, Schulte-Markwort, \& Graf Schimmelmann, 2008). Forty percent of variance in body mass index (BMI) was explained by eating problems. Further cross-sectional studies also found a higher frequency of dietary restraint in overweight children (Braet \& van Strien, 1997; Schacht, Richter-Appelt, Schulte-Markwort, Hebebrand, \& Graf Schimmelmann, 2006) and a higher likelihood to be overweight in boys and girls with higher scores in restrained eating (Snoek et al., 2007; Wardle et al., 1992; Lluch, Herbeth, Méjean, \& Siest, 2000; van Strien \& Oosterveld, 2008). Higher degrees of restrained and emotional eating in overweight compared to normal-weight individuals were also found in a representative sample of the Dutch adult population (van Strien, 
Herman, \& Verheijden, 2009). Several longitudinal studies have found that dietary restraint can result in overeating and weight gain (Stice, Cameron, Killen, Hayward, \& Taylor, 1999; Field et al., 2003; Neumark-Sztainer et al., 2012). It has therefore been shown that dietary restraint is a risk factor for the development of overweight.

Some studies have suggested that not only is a higher BMI the result of restrained eating but it may also be the cause of restrained eating (Shunk \& Birch, 2004: Snoek, van Strien, Janssens, \& Engels, 2008 ). Restrained eating may be a way to try to deal with weight concerns and body dissatisfaction in overweight adolescents. Results of a meta-analysis (Stice, 2002) have shown that body mass was a significant predictor of dieting with small effects. In a longitudinal study with adolescent boys and girls (Snoek et al., 2008), BMI significantly predicted restrained eating in both genders. Restrained eating was assessed with the Dutch Eating Behavior Questionnaire (van Strien, Frijters, Bergers, \& Defares, 1986). A further longitudinal study has found that girls' overweight at age five was a risk factor for the development of dietary restraint (assessed with Dutch Eating Behavior Questionnaire (van Strien et al., 1986)) at age nine (Shunk \& Birch, 2004). Therefore, several crosssectional studies have shown that BMI and restrained eating are correlated. However, only a few studies have investigated whether BMI predicts the development of restrained eating.

Results regarding gender differences in restrained and emotional eating are not clear. In one study boys reported more emotional and restrained eating than girls (Schacht et al., 2006). Snoek et al. (2007) however, have found contradictory results with girls scoring higher on emotional and restrained eating than boys. Wardl et al. (1992) also found higher dietary restraint and emotional eating in girls than in boys.

Body dissatisfaction has been identified as an important predictor of eating problems (Stice, Mazotti, Krebs, \& Martin, 1998; Stice \& Shaw, 2002; Allen, Byrne, McLean, \& Davis, 2008). Body dissatisfaction has been found to be strongly associated with emotional eating, both cross-sectionally and prospectively (Johnson \& Wardle, 2005) and to be a predictor of restrained eating in preadolescents (Allen et al., 2008). Therefore, the association between body dissatisfaction and restrained and emotional eating already appears to be established in preadolescents.

Negative affect has shown to be a risk factor for eating pathology with higher caloric intake during phases of negative mood (Stice, 2002). This finding suggests that emotional symptoms might be related to emotional eating. Depression has found to be significantly related to emotional eating in females (Ouwens, van Strien, \& van Leeuwe, 2009). In a four year longitudinal study (van Strien, van der Zwaluw, \& Engels, 2010), a relationship between depressive feelings and emotional eating was found, particularly in girls. Stice and Bearman (2001) and Bearman and Stice (2008) suggested in their gender additive model that some factors, such as eating-related problems, are experienced only by adolescent girls and not by boys which may explain their higher risk of depressive symptoms. It is, however, unclear whether there are gender differences in the relationship between eating-related problems and depression. Some studies have found an association between depressive symptoms and restrained eating in females but not in males (Gillen et al, 2012), whereas others have suggested that this relationship exists in both genders (Crow, Eisenberg, Story, \& Neumark-Sztainer, 2006; Vaughan \& Halpern, 2010).

Only a few studies have investigated whether childhood BMI is a significant predictor of restrained eating in preadolescents (Snoek et al.. 2008). The aim of this study was therefore (1) to examine whether childhood $\mathrm{BMl}$ is a significant predictor of restrained eating in preadolescents, (2) to investigate gender differences in restrained and emotional eating and specifically, in the relationship between childhood BMI and restrained eating, and
(3) to determine whether emotional problems and body esteem were related to eating problems of preadolescents.

\section{Methods}

\section{Procedure}

Data were collected in the large longitudinal study Pathways to Peer Victimisation (National Research Programme 52, Grant No. 4052-69011). The sample was drawn from a representative sample of kindergarten and elementary school children from the Germanspeaking part of Switzerland (Alsaker, 2007). In the present paper. we use data from two measurement points of data collection. The first assessment was carried out when children were at kindergarten age (2004: $t 1$ ), with a follow-up when children were at age 12 (2010: $t 2$ ). Written parental consent was obtained from all participants. Additionally, children gave oral assent prior to the first assessment and were given the option to withdraw from the study at any time. Ethics approval was given by the ethics committee of the University of Bern.

From the original sample of $N=1019$ families who participated in the study when the children went to kindergarten in 2004, 904 (88.7\%) were contacted (valid addresses available) and questionnaires were sent to both parents and children. Participants were given the option to fill out the paper-pencil version of the survey or an identical online version and were therefore given an individual password and a link to the online survey. To reduce the age range, questionnaires for the second assessment were sent at two points in time of the year 2010, in April $(n=706)$ and in September $(n=198)$, at times when children were expected to be around 12 years old. About two weeks after sending out of the questionnaires a reminder letter was sent to all the families who had not responded. of the 904 families, $11.6 \%(n=105)$ actively declined to participate, $3.2 \%(n=29)$ had moved and letters were returned, and $37.5 \%(n=339)$ did not reply. The response rate of the 875 families that received our letter at $t 2$ was $48.9 \%(N=428)$.

We found significant attrition effects regarding family background and BMI. The children who dropped out of the study by t2 were on average from families with a lower socio-economic status, were more likely to have a migration background, and had a higher BMI. The ratio of boys to girls did not differ between the children who dropped out and the sample of this study.

\section{Participants}

In total, 428 families participated in the follow-up study (50\% female children) and their data were included in the current paper. At $t 1$ (kindergarten age), children were on average 5.9 years old $(S D=0.54$, range: $4.6-7.5$ ). At $t 2$, children were on average 12.0 years old $(S D=0.60$, range: $10.4-13.8$ ). The time lag between the first assessment and the current follow-up was on average 6.1 years $(\mathrm{SD}=0.40$, range: 5.2 and 6.7 years).

At the second measurement point $29 \%$ of the children were from families with migration background with one or both parents born outside of Switzerland. Parents (mothers or fathers) who completed the parent questionnaire at $t 2$ had a high educational level: $34 \%$ had a college or University degree; $59 \%$ had a professional or higher education degree; $7 \%$ had basic education (maximum: 9 years of schooling).

\section{Measures}

\section{Eating Pattern Inventory for Children}

For the assessment of restrained and emotional eating at time 2 , the Eating Pattern Inventory for Children (EPI-C) (Schacht et al., 
2006) was used. The EPI-C has been developed for preadolescents on the basis of the Eating Behavior and Weight Problems Inventory for Children (EWI-C) (Diehl, 1999) and has been shown to be a valid and reliable measure with a sample of German preadolescents (Schacht et al., 2006). Internal consistencies as computed by means of Cronbach's alpha were .93 for dietary restrained and .80 for emotional eating. The subscale emotional eating consists of four items and assesses eating behaviour used to cope with emotional distress (e.g. 'When I am afraid or worried I eat something'). The subscale dietary restraint consists of eight items assessing affective, cognitive, and behavioural aspects of dietary restraint such as fear of becoming overweight, concerns about food and weight and restrictions in food intake (e.g. 'I am very afraid of putting on weight'). All items were rated on a 4-point Likert scale ( $1=$ 'not at all' to $4=$ 'totally'). Cronbach's alpha in this study was .93 for girls and .94 for boys for restrained eating and.84 for girls and .88 for boys for emotional eating.

\section{Body mass index (BMI)}

Height and weight of the children was measured by research assistants at the first point of assessment when the children were on average 6 years old. At the second point of assessment (2010), when children were on average 12 years old, they were asked to report their weight and height. Weight and height were assessed with self-reports at $t 2$ because participants filled out questionnaires at home and we did not have direct contact with the participating families. Additionally, parents were asked about their child's weight and height at $t 2$. Body mass index $\left(\mathrm{kg} / \mathrm{m}^{2}\right)$ was calculated. The correlation between BMl reported by the parents and by the child was $r=.95$ for girls and $r=.94$ for boys.

\section{Body esteem}

The appearance subscale of the Body Esteem Scale for Children (Mendelson \& White, 1982, 1993-1994) was used to assess body esteem at time 2. The Body Esteem Scale was designed to assess children's overall evaluation of their bodies, attitudes and feelings about bodies and appearance. The appearance subscale consists of 12 Items (e.g. 'I worry about the way I look' or 'I am proud of my body'). Items were rated on a 4-point Likert scale ( 1 = 'strongly disagree' to $4=$ 'strongly agree') with high values indicating a high body esteem. The Body Esteem Scale has been shown to be a valid and reliable instrument with good internal consistency for the assessment of positive evaluations about one's body and appearance and can be used in children and adolescents (Mendelson \& White, 1982, 1993-1994; Mendelson, Mendelson, \& White, 2001). In this study Cronbach's alpha was .93 for girls and .90 for boys.

\section{Emotional symptoms}

Children completed the emotional symptoms subscale of the Strengths and Difficulties Questionnaire (SDQ) (Goodman, 1997, 2001 ) at time 2 . The emotional symptoms subscale consists of 5 items. Items were rated on a three-point-scale ('not true', 'somewhat true', and 'certainly true'). The SDQ is a widely used, reliable, and valid measure of the psychopathology of children and adolescents (Goodman, 2001). In this study Cronbach's alpha was low with .57 for girls and .68 for boys.

\section{Statistical analysis}

Descriptive analyses were calculated and t-tests for independent samples were used to examine gender differences between means of age, BMI, emotional eating, restrained eating, body esteem, and emotional symptoms. Pearson correlations between variables were calculated for boys and girls separately. Separate hierarchical regression analyses were computed with restrained and emotional eating at time 2 as dependent variables. Residual change scores of BMI time 1 to BMI time 2 were calculated to remove existing associations between change in BMI and initial status of BMI. In each of these analyses, $t 1 \mathrm{BMI}$, standardised residual change scores of BMI, $t 2$ body esteem, $t 2$ emotional symptoms, $t 1$ age, $t 2$ age and gender were entered as independent variables at the first step. At the second step, the interaction effects were examined for BMI and gender, emotional symptoms and gender, residual change scores and gender, as well as body esteem and gender. Gender was dummy coded ( $0=$ girls, $1=$ boys).

\section{Results}

No significant differences were found in age at $t 1$ and $t 2$ or BMI at $t 1$ or $t 2$ between boys and girls (see Table 1 ). Gender differences in means were found for emotional eating, restrained eating, emotional symptoms and body esteem with girls having higher values than boys on emotional eating, restrained eating, ernotional symptoms and lower values in body esteem (Table 1 ).

Correlations between variables are shown for girls and boys separately in Table 2 . Correlations between $t 2$ restrained and emotional eating were .34 for both genders. Emotional symptoms ( $t 2)$ did not correlate significantly with $t 2$ restrained eating in boys but there was a significant weak correlation between the two variables in girls. Emotional eating ( $t 2)$ did not correla te significantly with $t 1 \mathrm{BMI}$, neither in boys nor in girls. The correlation between $t 2$ body esteem and $t 2$ restrained eating was strong in both genders. There was a high correlation between $\mathrm{t} 1 \mathrm{BMI}$ and $t 2 \mathrm{BMI}$ in both genders.

The results of the multiple regression analysis examining associations between $t 1 \mathrm{BMI}$, residual change score BMI, $t 2$ body esteem, $t 2$ emotional symptoms, gender, age, and $t 2$ emotional or $t 2$ restrained eating, showed that $t 1 \mathrm{BMI}$, change in BMI and $t 2$ body esteem significantly predicted $t 2$ restrained eating (Table 3 ). $t 2$ Body esteem and $t 2$ emotional symptoms were significant predictors of $t 2$ emotional eating. $t 1$ BMI did not significantly predict t2 emotional eating. Gender was also not a significant predictor of $t 2$ restrained or emotional eating. The non-significant gender interaction effects examined in step 2 of the regression indicated that the effects of $t 1 \mathrm{BMI}, t 2$ body esteem, and $t 2$ emotional symptoms on restrained or emotional eating did not significantly differ for boys and girls. The significant residual change score of BMI shows that there was a tendency in girls with an increase in BMI between $t 1$ and $t 2$ to have higher emotional eating compared to boys. This was, however, not a significant gender difference because the interaction effects were not significant.

Table 1

Results of independent groups t-test for comparison of age, body mass index, restrained eating, emotional eating, emotional symptoms, and body esteem by gender including descriptive statistics.

\begin{tabular}{|c|c|c|c|c|c|c|}
\hline & \multicolumn{2}{|l|}{ Girls } & \multicolumn{2}{|l|}{ Boys } & \multirow[b]{2}{*}{$t$} & \multirow[b]{2}{*}{$d f$} \\
\hline & Mean & SD & Mean & SD & & \\
\hline Age $t 1$ & 5.90 & .54 & 5.87 & .54 & .53 & 426 \\
\hline Age $t 2$ & 11.97 & .57 & 11.95 & .64 & .31 & 426 \\
\hline Body mass index $t 1$ & 15.59 & 1.73 & 15.69 & 1.43 & -.70 & 412 \\
\hline Body mass index $t 2$ & 17.87 & 2.57 & 17.94 & 2.62 & -.29 & 406 \\
\hline Emotional eating $t 2$ & 1.52 & .70 & 1.34 & .55 & $3.10^{\circ}$ & 408 \\
\hline Restrained eating $t 2$ & 1.57 & .70 & 1.42 & .66 & $2.34^{\circ}$ & 412 \\
\hline Emotional symptoms $t 2$ & 1.45 & .36 & 1.36 & .36 & $2.53^{\circ}$ & 415 \\
\hline Body esteem $t 2$ & 3.11 & .59 & 3.34 & .51 & $-4.28^{-4+}$ & 409 \\
\hline
\end{tabular}

* $p<.05$.

$* \begin{aligned} & p<.001 \\ & p<.\end{aligned}$ 
Table 2

Pearson correlations between restrained eating, emotional eating, BMl $t 1, \mathrm{BMI} t 2$, emotional symptoms, and body esteem by gender.

\begin{tabular}{|c|c|c|c|c|c|c|}
\hline & Restrained eating & Emotional eating & BMI $t 1$ & BMI $t 2$ & SDQ emotional sympt. $t 2$ & Body esteem $t 2$ \\
\hline Res trained eating $t 2$ & - & $.34^{.10}$ & $.44^{*+\infty}$ & $.57^{62 x}$ & $.23^{2 *}$ & $-.63^{202}$ \\
\hline Emotional eating $t 2$ & $.34^{\cdots \cdots}$ & - & .12 & $.24^{n-x}$ & $.29^{\ldots}$ & $-.30^{\mathrm{mo}}$ \\
\hline BMI $\mathrm{tI}$ & $.34^{\cdots}$ & -.03 & - & $.64^{-1+}$ & .05 & $-.28^{n}$ \\
\hline BMI 12 & $.55^{\mathrm{n}}$ & .05 & $.68^{\prime \cdots}$ & - & .08 & $-.35^{\prime \prime}$ \\
\hline Emotional symptoms $t 2$ & .13 & $.22^{s e}$ & $\ldots .09$ & -.03 & $-\infty$ & $-.30^{\prime \prime \prime}$ \\
\hline Body esteem $t 2$ & $-.53^{* 4}$ & $-.24^{w *}$ & -.13 & $-.31^{\cdots}$ & $-.36^{5+*}$ & - \\
\hline
\end{tabular}

Values for girls are above the diagonal and for boys bellow the diagonal.

$\ldots p<.01$.

$\approx \cdots p<001$.

Table 3

Multiple regression analysis predicting restrained eating and emotional eating.

\begin{tabular}{|c|c|c|c|c|}
\hline & Restrained eating $t 2$ & & Emotional eating $t 2$ & \\
\hline \multicolumn{5}{|l|}{ Step 1} \\
\hline BMI $t 1$ & $.31^{\cdots \infty}$ & & .02 & \\
\hline SRCS BMI & $.29^{* n}$ & & .09 & \\
\hline Body esteem $t 2$ & $-.43^{\cdots-}$ & & $-.16^{\times 0}$ & \\
\hline Emotional symptoms $t 2$ & .03 & & $.19^{* \ldots+}$ & \\
\hline Gender & -.03 & & -.09 & \\
\hline Age $t$ & -.09 & & -.04 & \\
\hline Age $t 2$ & .05 & $R^{2}=.50$ & .06 & $R^{2}=.13$ \\
\hline \multicolumn{5}{|l|}{ Step 2} \\
\hline BMI $t 1$ & $32^{* \cdots *}$ & & .07 & \\
\hline SRCS BMI & $.26^{* * *}$ & & $.17^{*}$ & \\
\hline Body esteem $t 2$ & $-.45^{\cdots}$ & & $-.16^{*}$ & \\
\hline Emotional symptoms $t 2$ & .06 & & $.24^{* \prime}$ & \\
\hline Gender & .14 & & .62 & \\
\hline Age $t 1$ & -.10 & & -.03 & \\
\hline Age $t 2$ & .05 & & .06 & \\
\hline Gender $\times$ BMI $t 1$ & -.21 & & -.53 & \\
\hline Gender $\times$ SRCS BMI & .04 & & -.10 & \\
\hline Gender $x$ body esteem $t 2$ & .15 & & -.01 & \\
\hline Gender $x$ emotional symptoms $t 2$ & -.11 & $R^{2}=.50$ & -.19 & $R^{2}=.14$ \\
\hline
\end{tabular}

Values are standardised betas; $t 1=2004, t 2=2010$; SRCS BMI: Standardised residual change score BMI $t 1$ to BMI $t 2$.

$p<.05$.

${ }^{4 .} p<.01$.

$\cdots p .001$.

\section{Discussion}

The current study examined six-year longitudinal associations between childhood BMI and preadolescent restrained and emotional eating in order to identify if childhood BMI is a risk factor for the development of eating problems. Our findings indicated that childhood BMI significantly predicted restrained but not emotional eating six years later. A bigger change of BMI in the six years led to significantly more restrained eating in preadolescence. Furthermore, lower body esteem of the 12-year-olds was significantly associated with higher restrained and emotional eating. Higher emotional symptoms of the 12-year-olds were significantly associated with higher emotional eating.

The results of our study extend former cross-sectional results about the relationship between overweight and disordered eating (Schacht et al., 2006; Snoek et al., 2007; Schuetzmann et al., 2008 ) by showing, with a longitudinal design, that BMI in kindergarten was a significant predictor of restrained eating six years later. This was consistent with the results of the 2 years longitudinal study with 13-16 years old adolescents by Snoek et al. (2008). Therefore, overweight seems not only to be a result of restrained eating (Haines et al., 2007) but also a risk factor for the development of restrained eating. Restrained eating at age 12 was significantly more likely in girls and boys with a higher BMl at age six and in preadolescents with a higher increase in BMI over the six years. Already in childhood, BMI seems to have a significant influence on eating problems which might, if not prevented or treated early in life, have negative consequences on psychological wellbeing or health later in life.

Consistent with the results of Snoek et al. (2007), girls had higher values of restrained and emotional eating than boys. However, when controlling for BMI, body esteem and emotional symptoms, gender was no longer a significant predictor of restrained or emotional eating. Lower body esteem and higher emotional symptoms might explain the higher values of restrained and emotional eating in girls. Furthermore, the interaction effect between gender and $\mathrm{BMI}$ on restrained or emotional eating was not significant.

As found earlier (Johnson \& Wardle, 2005), body esteem was strongly associated with restrained and emotional eating in this study. Longitudinal studies (Stice et al., 1998; Allen et al., 2008) have shown that body esteem significantly predicted eating behaviour. Body esteem is therefore an important protective factor in relation to the development of eating problems and this seems to be true for boys and for girls. No interaction effect between gender and body esteem on restrictive or emotional eating was found in this study.

The gender additive model suggests that problems experienced to a higher extend by females, such as eating-related problems, might explain the higher risk of depressive symptoms in females (Stice \& Bearman, 2001; Bearman \& Stice, 2008). Gender differences in depression with higher emotional symptoms in girls than in boys have been found to emerge during adolescence by age 
13-14 (Nolen-Hoeksema, 1994; Wade, Cairney, \& Pevalin, 2002). In this study higher emotional symptoms in girls were already prevalent in preadolescence at age 12 . Gender differences in emotional symptoms might be an indication of the development of gender differences in depression one or two years later. Although there was a significant relationship between emotional symptoms and emotional eating, the interaction effect between emotional symptoms and gender on emotional eating was not significant. Due to the assessment of emotional symptoms at $t 2$ only, the results of our study do not allow conclusions about causal relationships between emotional symptoms and emotional eating and it remains unclear if, as in the gender additive model suggested, higher eating-related problems in girls than in boys might contribute to the explanation of gender differences in depression, or, as expected in our model, emotional symptoms lead to emotional eating. Our results do, however, suggest that adolescents with emotional symptoms seem to be more likely to show emotional eating rather than restrictive eating.

Limitations of this study were the low internal consistency of the emotional symptom subscale of the SDQ and that body esteem and emotional symptoms were not assessed at the first time of assessment due to difficulties to assess these constructs in 6 year-olds. Therefore longitudinal relationships between these variables and eating problems are not known. Due to lack of manipulation of the independent variables results cannot be interpreted as causal. The results have to be interpreted on the basis of a drop-out rate of $51 \%$ with significant attrition effects in relation to family background and BMI. At the second time of assessment families' socio-economic status was higher, fewer families had a migration background, and children had on average a lower BMI compared to the original sample. At the second measurement point weight and height were self-reported by parents and children. Although the correlation between BMI reported by parents and children were high it might be that weight was underestimated and height overestimated, particularly in overweight children (Elgar, Roberts, Tudor-Smith, \& Moore, 2005; Larsen, Ouwens, Engels, Eisinga, \& van Strien, 2008; Seghers \& Claessens, 2010). However, the correlations between self-reported and measured height and weight have found to be high in adolescents (Elgar et al.. 2005).

\section{Conclusions}

Our results indicated that boys and girls with a higher BMI in childhood and a higher increase of BMI from childhood to preadolescence were at a higher risk to develop restrained eating in preadolescence. This increases the risk to maintain or develop overweight because restrained eating is not only a risk factor for the development of eating disorders (Fairburn et al., 2005), but also for overweight (Haines et al., 2007). Early prevention of overweight already in childhood is therefore particularly important to avoid a vicious cycle between overweight and disordered eating. There is still a need to improve the effectiveness of obesity prevention programs (Stice, Shaw, \& Marit, 2006) and to find more effective strategies to influence children's eating behaviour and weight on a long run as found in a meta-analytic review of obesity prevention programs for children and adolescents. The results of the current study contribute to this field of research by highlighting the importance of childhood BMI in relation to restrained eating. For the understanding of higher prevalence of disordered eating in girls than in boys, body esteem and emotional symptoms might be relevant factors. Further longitudinal studies are necessary to investigate if lower body esteem and higher emotional symptoms in girls contribute to the explanation of gender differences in disordered eating.

\section{References}

Allen, K. L., Byrne, S. M. McLean, N. J., \& Davis, E. A. (2008). Overconcern with weight and shape is not the same as body dissatisfaction. Evidence from prospective study of pre-adolescent boys and girls. Body Imoge, 5. 261-270.

Alsaker, F. (2007). Pathways to victimization and a multisetting intervention. Research Report. Bern, Swiss National Science Foundation. NFP52.

Bearman, S. K., \& Stice, E. (2008). Testing a gender additive model. The role of body image in adolescent depression. Journal of Abnormal Child Psychology. 36. $1251-1263$.

Braet, C., \& van Strien, T. (1997). Assessment of emotional, externally induced and restrained eating behaviour in nine to twelve-year-old obese and non-obese children. Behaviour Research and Therapy, 35, 863-873.

Crow, S., Eisenberg, M. E., Story, M., \& Neumark-Sztainer, D. (2006). Psychosocial and behavioral correlates of dieting among overweight and non-overweight adolescents. Journal of Adolescent Health، 38, 569-574.

Diehl, J. M. (1999). Einstellungen zu Essen und Gewicht bei 11-bis 16jaehrigen Adoleszenten. [Attitude to eating and body weight in 11-to16year-old adolescents.]. Schweizerische Medizinische Wochenschrift, 129. 162-175.

Elgar. F. J. Roberts, C., Tudor-Smith. C.. \& Moore. L. (2005). Validity of self-reported height and weight and predictors of bias in adolescents. Joumal of Adolescen Health, 37, 371-375.

Fairburn, C. G., Cooper, Z., Doll, H. A., \& Davies, B. A. (2005). Identifying dieters who will develop an eating disorder. A prospective, population-based study. The American Journal of Psychiatry. 162, 2249-2255.

Field, A. et al. (2003). Relation between dieting and weight change among preadolescents and adolescents. Pediatrics, 112, 900-906.

Gillen, M. M., Markey, C. N., \& Markey, P. M. (2012). An examination of dieting bahaviors among adults. Links with depression. Eating Behaviors, 13, 88-93.

Goodman, R. (1997). The strengths and difficulties questionnaire. A research note Journal of Child Psychology and Psychiatry and Allied Disciplines, 38, 581-586.

Goodman, R. (2001). Psychometric properties of the strengths and difficulties questionnaire (SDQ). Journal of the American Academy of Child and Adolescen Psychiatry. 40, 1337-1345.

Haines, J. Neumark-Sztainer, D., Wall, M., \& Story, M. (2007). Personal, behavioral and environmental risk and protective factors for adolescent overweight. Obesity, 15, 2748-2760.

Johnson, F. \& Wardle. J. (2005). Dietary restraint, body dissatisfaction, and psychological distress. A prospective analysis. Joumal of Abnormal Psychology. 114. 119-125.

Larsen, J. K., Ouwens, M., Engels, R. C. M. E., Eisinga, R., \& van Strien, T. (2008) Validity of self-reported weight and height and predictors of weight bias in female college students. Appetite, 50, 386-389.

Lluch. A., Herbeth, B., Mẻjean, L., \& Siest. G. (2000). Dietary intakes, eating style and overweight in the Stanislas Family Study. International Journal of Obesity, 24 1493-1499.

Mendelson, B. K., Mendelson, M. J. \& White, D. R. (2001). Body-esteem scale for adolescents and adults. Joumal of Personality Assessment, 76, 90-106.

Mendelson, B. K. \& White, D. R. (1982). Relation between body-esteem and self esteem of obese and normal children. Perceptual and Motor Skills, 54, 899-905.

Mendelson, B. K., \& White, D. R. (1993-1994). Manual for the Body-Esteem Scale for children. Research, Bulletin, 12,1-10.

Must, A., \& Strauss, R. S. (1999). Risks and consequences of childhood and adolescent obesity. International journal of obesity, 23, S2-11.

Neumark-Sztainer, D., Story, M. Hannan, P. J., Perry, C. L. \& Irving, L. M. (2002) Weight-related concerns and behaviors among overweight and nonoverweight adolescents. Implications for preventing weight-felated disorders. Archive of Pediatrics \& Adolescent Medicine, 156, 171-178.

Neumark-Sztainer, D., Wall, M., Story, M., \& Standish, A. R. (2012). Dieting and unhealthy weight control behaviors during adolescence. Associations with 10 year changes in body mass index. Journal of Adolescent Health, 50, 80-86.

Nolen-Hoeksema, S. (1994). An interactive model for the emergence of gender differences in depression in adolescence. Joumal of Research on Adolescence, 4 $519-534$

Ouwens, M. A., van Strien, T., \& van Leeuwe, J. F. J. (2009). Possible pathways between depression, emotional and external eating. A structural equation model. Appetite, $53,245-248$.

Polivy, I. \& Herman, C. P. (1985). Dieting and bingeing. A causal analysis. American Psychologist, 40, 193-204.

Schacht. M. Richter-Appelt, H. Schulte-Markwort, M. Hebebrand, J. \& Graf Schimmelmann, B. (2006). Eating pattern inventory for children. A new selfrating questionnaire for preadolescents. Journal of Clinical Psychology, 62, 1259-1273.

Schuetzmann, M. Richter-Appelt. H.. Schulte-Markwort, M., \& Graf Schimmelmann, B. (2008). Associations among the perceived parent-child relationship, eating behavior, and body weight in preadolescents. Resutls from a community-based sample. Joumal of Pediatric Psychology, 33, 772-782.

Seghers, J.\& \& Claessens, A. L. (2010). Bias in self-reported height and weight in preadolescents. Journal of Pediatrics, 157, 911-916.

Shunk, J. \& Birch, L. (2004). Girs at risk for overweight at age 5 are at risk for dietary restraint, disinhibited overeating, weight concerns, and greater weight gain from 5 to 9 years. Journal of the American Dietetic Association, 104, 1120-1126.

Snoek, H. M., van Strien, T., Janssens, I. M. A. M., \& Engels, R. C. M. E. (2007). Emotional, external, restrained eating and overweight in Dutch adolescents. Scandinavian Journal of Psychology. 48, 23-32. 
Snoek, H. M., van Strien, T., Janssens, J. M. A. M., \& Engels, R. C. M. E. (2008) Restrained eating and BMI. A longitudinal study among adolescents. Health Psychology, 27, 753-759.

Stice, E. (1994). Review of the evidence for a sociocultural model of bulimia nervosa and an exploration of the mechanisms of action. Clinical Psychology Review, 14, 633-661.

Stice, E. (2002). Risk and maintenance factors for eating pathology. A meta-analytic review. Psychological Bulletin, 128, 825-848.

Stice, E. Agras, W. S. \& Hammer, L. D. (1999). Risk factors for the emergence of childhood eating disturbances. A five-year prospective study. International Journal of Eating Disorders, $25,375-387$.

Stice, E. \& Bearman. S. K. (2001). Body-image and eating disturbances prospectively predict increases in depressive symptoms in adolescent girls. A growth curve analysis. Developmental Psychology, 37, 597-607.

Stice, E, Cameron, R. Killen, ]. Hayward, C \& Taylor, C (1999), Naturalistic weightreduction efforts prospectively predict growth in relative weight and onset of obesity among female adolescents. Journal of Consulting and Clinical Psychology. obesity among
$67.967-974$

Stice, E, Mazotti, L., Krebs, M., \& Martin, S. (1998). Predictors of adolescent dieting behaviors. A longitudinal study. Psychology of Addictive Behaviors, 12, 195-205.

Stice, E., \& Shaw, H. E (2002). Role of body dissatisfaction in the onset and maintenance of eating pathology. A synthesis of research findings. Journal of Psychosomatic Research, 53, 985-993.

Stice, E., Shaw, H.. \& Marit, C. N. (2006). A meta-analytic review of obesity prevention programs for children and adolescents. The skinny on interventions that work. Psychological Bulletin, 132, 667-691.
Stovitz. S. D., Pereira, M. A., Vazquez, G., Lytle, L. A., \& Himes, J. H. (2008). The interaction of childhood hight and childhood BMI in the prediction of young adult BMl. Obesity, 16, 2336-2341.

van Strien, T. Frijters, J., Bergers, G.. \& Defares, P. (1986). The dutch eating behavior questionnaire (DEBQ) for assessment of restrained, emotional, and external eating behavior. International Journal of Eating Disorders, 5. 295-315.

van Strien, T., Herman, C. P., \& Verheijden, M. W. (2009). Eating style, overeating and overweight in a representative Dutch sample. Does external eating play a role? Appetite, 52, 380-387.

van Strien, T., \& Oosterveld, P. (2008). The children's DEBQ for assessment of restrained, emotional, and external eating in 7- to 12-year-old children. International Journal of Eating Disorders. 41, 72-81.

van Strien, T., van der Zwaluw, C. S. \& Engels, R. C. M. E. (2010). Emotional eating in adolescents. A gene (SLC6A4/5-HTT) - Depressive feelings interaction analysis. Journal of Psychiatric Research, 44, 1035-1042.

Vaughan, C. A., \& Halpern, C. T. (2010). Gender differences in depressive symptoms during adolescence. The contributions of weight-selated concerns and behaviors. Journal of Research on Adolescence, 20,389-419.

Wade, T. J., Cairney. J., \& Pevalin, D. J. (2002). Emergence of gender differences in depression during adolescence. National panel results from the three countries. Joumal of the American Academy of Child E' Adolescent Psychiatry, 41, 190-198.

Wardle, J. et al. (1992). Eating style and eating behaviour in adolescents. Appetite $18,167-183$. 